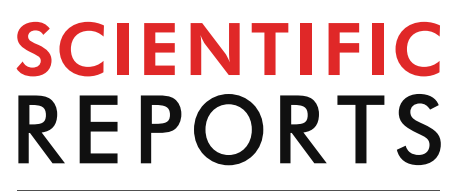

natureresearch

Check for updates

\title{
OPEN Author Correction: Fish proliferation and rare-earth deposition by topographically induced upwelling at the late Eocene cooling event
}

\author{
Junichiro Ohta, Kazutaka Yasukawa, Tatsuo Nozaki, Yutaro Takaya, Kazuhide Mimura, \\ Koichiro Fujinaga, Kentaro Nakamura, Yoichi Usui, Jun-Ichi Kimura, Oing Chang \& \\ Yasuhiro Kato
}

Correction to: Scientific Reports https://doi.org/10.1038/s41598-020-66835-8, published online 18 June 2020

The original version of this Article contained typographical errors in the Methods section.

As a result, under the subheading "Os and Re isotope analyses",

"In addition to the samples from the study cores, we measured several uppermost sediment samples (0.00-0.02 mbsf) collected near core KR13-02 PC05 on cruises KR13-02 and MR14-E02 (Supplementary Table S3) to confirm that our Os isotopic data represented marine ${ }^{187} \mathrm{Os} /{ }^{188} \mathrm{Os}$ values. The ${ }^{187} \mathrm{Os} /{ }^{188} \mathrm{Os}$ ratios of these samples ranged from $0.954 \pm 0.011$ to $0.997 \pm 0.012$ (Supplementary Table S3)."

now reads:

"In addition to the samples from the study cores, we measured several uppermost sediment samples $(0.00-0.02$ mbsf) collected near core KR13-02 PC05 on cruises KR13-02 and MR14-E02 (Supplementary Table S2) to confirm that our Os isotopic data represented marine ${ }^{187} \mathrm{Os} /{ }^{188} \mathrm{Os}$ values. The ${ }^{187} \mathrm{Os} /{ }^{188} \mathrm{Os}$ ratios of these samples ranged from $0.954 \pm 0.011$ to $0.997 \pm 0.012$ (Supplementary Table S2)."

Furthermore, under the subheading "Marine ${ }^{187} \mathrm{Os} /{ }^{188} \mathrm{Os}$ curve since $40 \mathrm{Ma}$ ”,

"To complement the reference curve, we employed a long-term record of marine ${ }^{187} \mathrm{Os} /{ }^{188}$ Os ratios obtained from a Fe-Mn crust in the Pacific ${ }^{63}$ refined by the thallium isotope record in the crust ${ }^{16}$ (Supplementary Fig. S1)."

now reads:

"To complement the reference curve, we employed a long-term record of marine ${ }^{187} \mathrm{Os} /{ }^{188}$ Os ratios obtained from a Fe-Mn crust in the Pacific ${ }^{63}$ refined by the thallium isotope record in the crust ${ }^{16}$ (Supplementary Fig. S4)."

Additionally, in the Supplementary Information file originally published with this Article, Supplementary Tables S1-S3 were omitted.

These errors have now been corrected in the HTML and PDF versions of this Article and in the accompanying Supplementary Information. 


\begin{abstract}
(c) Open Access This article is licensed under a Creative Commons Attribution 4.0 International License, which permits use, sharing, adaptation, distribution and reproduction in any medium or format, as long as you give appropriate credit to the original author(s) and the source, provide a link to the Creative Commons license, and indicate if changes were made. The images or other third party material in this article are included in the article's Creative Commons license, unless indicated otherwise in a credit line to the material. If material is not included in the article's Creative Commons license and your intended use is not permitted by statutory regulation or exceeds the permitted use, you will need to obtain permission directly from the copyright holder. To view a copy of this license, visit http://creativecommons.org/licenses/by/4.0/.
\end{abstract}

(C) The Author(s) 2020 